\title{
Evaluation of the interpretation of ceilometer data with RASS and radiosonde data
}

\author{
Stefan Emeis ${ }^{1}$, Klaus Schäfer ${ }^{1}$, Christoph Münkel ${ }^{2}$ \\ ${ }^{1}$ Karlsruhe Institute of Technology, Institute for Meteorology and Climate Research, Kreuzeckbahnstr. 19, \\ 82467 Garmisch-Partenkirchen, Germany, stefan.emeis@kit.edu
${ }^{2}$ Vaisala GmbH, Schnackenburgallee41d, 22525 Hamburg, Germany, christoph.muenkel@vaisala.com
}

\begin{abstract}
Ceilometer backscatter information is evaluated by comparison with parallel measurements. Data are presented from two years of combined ceilometer and RASS measurements at the same site and from comparison with a nearby $(60 \mathrm{~km})$ radiosonde for largerscale humidity information. This evaluation is designed to make MLH monitoring from ceilometer data more reliable. Finally, the detection of volcanic ash clouds with ceilometers is addressed.
\end{abstract}

\section{INTRODUCTION}

Ceilometers (and other optical ground-based remote sensing devices) increasingly become standard devices for monitoring the vertical structure of the atmospheric mixing-layer and especially detecting its height (MLH). The detection of MLH from ceilometer data is based on the basic assumption that the aerosol content in the well-mixed layer is higher than in the atmospheric layers above. Hence, vertical profiles of the optical backscatter intensity are analysed for the occurrence of negative intensity gradients in order to detect MLH [1]. Although this basic assumption is usually true, it has also to be assumed that the vertical aerosol distribution follows the vertical structure of the atmospheric boundary layer without much delay. But even if this happens, additional influences on the optical backscatter intensity have to be taken into account when interpreting time-height cross-sections of optical backscatter intensity from ceilometer measurements. Two examples of such possible influences are the advection of clear air masses by nocturnal low-level jets and larger changes in atmospheric relative humidity. Furthermore, the advection of aerosol from natural sources such as desert dust or volcanic ash clouds can modify the results.

The investigation of such influences requires parallel measurements of vertical profiles of wind speed and humidity. A first attempt for data inter-comparison has been presented at the previous ISARS in 2008 [2].

\section{INSTRUMENTATION}

The ceilometer, a Vaisala CL31, is a ceilometer with one optical axis [3] which allows for observations from a few tens of metres up to several kilometres above ground with a vertical resolution of about $10 \mathrm{~m}$. The instrument is sited on industrial grounds at the northern edge of the town of Augsburg, Germany.

The METEK-RASS used for direct comparisons is a Doppler-RASS or SODAR-RASS [3] that measures profiles of wind speed, wind direction, variance of the vertical wind component and of acoustic temperature with a vertical resolution of $20 \mathrm{~m}$ up to a height of 540 $\mathrm{m}$. The RASS is operated at this site since spring 2008. The ceilometer mentioned before has been installed several months later at a distance of about $5 \mathrm{~m}$ to the RASS. This joint operation has been designed especially for an instrument intercomparison.

Humidity information is not available from groundbased remote sensing but is taken from radiosonde soundings of the German Weather Service at Oberschleißheim near Munich. This station is about $60 \mathrm{~km}$ east of Augsburg and the radiosonde is launched twice a day shortly after midnight and shortly after noon local time (00 and 12 GMT).

\section{RESULTS}

\subsection{Comparison to temperature information}

The first example (Fig. 1) shows data from February 5 , 2009 , a clear winter day and a comparison to temperature information from radiosonde and SODAR-RASS measurements.

The top frame of Fig. 1 gives the optical backscatter intensity measured by the ceilometer. The bold (nearly horizontal) blue lines indicate cloud bases, the bold (nearly horizontal) black line the mixing-layer height derived from an automated algorithm [1]. The thin (nearly vertical) lines with the attached numbers give relative humidity (in \%) and potential temperature (in $\mathrm{K})$ from radiosonde data at Oberschleißheim. We see that there was a fog layer (brown colour) near the ground in the night and the early morning until about $9.00(\mathrm{GMT}+1)$. Then the fog layer rises and the clouds finally disappear shortly before noon. In the afternoon a well-mixed polluted surface layer up to about $300 \mathrm{~m}$ height develops. Between 18.00 and 21.00 a new shallow surface layer comes into existence. The radiosonde profiles clearly confirm the ceilometer data by showing a large increase in potential temperature (and a related decrease in relative humidity) at the top of the fog layer at night and at the top of the wellmixed layer at noon.

Because radiosonde data are available only twice a day, comparison is also made to RASS and SODAR data. The middle frame of Fig. 1 shows potential temperature measured with the RASS. The fog layer is indicated by the very low (dark blue) temperatures in the night and in the early morning. The second cloud layer seen in the night in the ceilometer data at about $200 \mathrm{~m}$ above ground is confirmed by a respective increase in potential temperature with height (from greenish to reddish colours). The rise of the fog layer and the dissolution of the clouds before noon are con- 
firmed by the disappearance of the surface cold air mass (blue colour). The top of the mixed layer in the afternoon is marked by a sharp vertical temperature increase (inversion, green to red) and the newly forming surface layer in the evening by a newly forming cold air mass close to the surface (Light and later dark blue). The temperature inversion which marked the top of the daytime mixed layer persists as a lifted inversion at about $250 \mathrm{~m}$ into the night, i.e. a residual layer is present between the newly forming surface layer and the persisting lifted inversion.
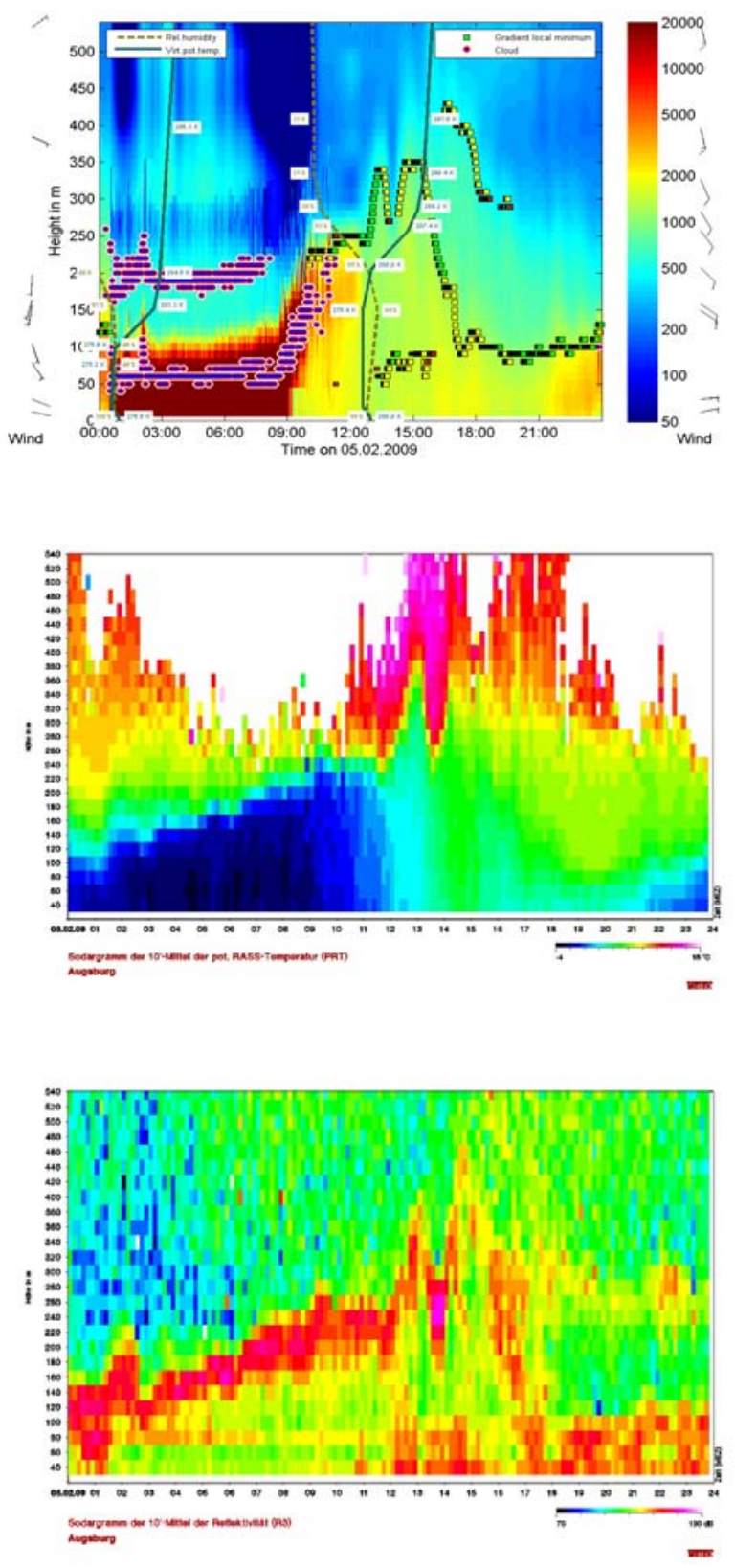

Figure 1. Time-height sections (one day from midnight to midnight, 40 to $540 \mathrm{~m}$ above ground) of optical backscatter intensity (top), potential temperature (middle) and acoustic backscatter intensity (below) over Augsburg, Germany on February 5, 2009. Red colours: high values, blue colours: low values. Time is GMT plus 1 which is close to local time. (See text for further details)
This residual layer is also visible from the lower frame in Fig. 1 which presents the acoustic backscatter intensity measured by the SODAR part of the RASS. Acoustic backscatter basically depends on small-scale (turbulent) temperature fluctuations and gradients and on strong temperature inversions.

The lower image clearly shows three features as maxima (red colours) of the acoustic backscatter intensity: the top of the fog layer in the morning, the top of the mixed layer in the afternoon (which persists into the next night) and the newly forming stable layer close to the surface after 17.00. The red colours close to the surface around noon are indicating a shallow super-adiabatic layer due to solar insolation and radiative surface heating.

\subsection{Comparison to wind information}

Advection can be a decisive influencing factor on timeheight cross-sections of optical backscatter intensity (as it is so for acoustic backscatter intensities recorded with a SODAR). Advection surely plays an important role in nights with strong low-level jets. These lowlevel jets can advect air masses over longer distances. Thus, it is easily possible that clean remote air masses are advected over otherwise polluted areas.

Figure 2 shows an example for such an influence of a low-level jet from September 8/9, 2009. The top frame in Fig. 2 shows the optical backscatter intensity from the ceilometer measurements. It was a clear night with no clouds. In the afternoon before the convective boundary layer $(\mathrm{CBL})$ has reached a top height of about $1000 \mathrm{~m}$ (dots in the optical backscatter image indicate mixing-layer heights from an automated MLHalgorithm described in [1]). In this CBL the potential temperature was constant with height (see lowest frame in Fig. 2 for potential temperature derived from the RASS).

The most prominent features in the optical backscatter time-height cross-section are the dark blue patterns reaching down to heights of about $1000 \mathrm{~m}$ above ground at night. These blue patterns, which mean very low backscatter intensity, indicate very clean air masses. The occurrence of these clean air masses seems to be correlated with high wind speeds above a stably stratified nocturnal boundary layer (NBL). Wind speed from the SODAR part of the RASS is plotted in the middle frame of Fig. 2. Unfortunately, the vertical range of the wind information is quite limited, because the signal-to-noise ratio was too low for a Doppler analysis of the backscattered acoustic signals. The maximum wind speed recorded (purple colour) was about $19 \mathrm{~m} / \mathrm{s}$ at $200 \mathrm{~m}$ height on September 900.50 $G M T+1$. Probably wind speeds were even higher in greater heights. The strong stability of the NBL is visible from the strong vertical increase of potential temperature (lowest frame in Fig.2). Dark blue colours correspond to $12^{\circ} \mathrm{C}$, dark red to $22^{\circ} \mathrm{C}$ and purple to $26^{\circ} \mathrm{C}$. The white area in the potential temperature time-height cross-section is a secondary proof for high wind speeds, because high wind speeds blow the acoustic signal of the RASS out of the focus of the electro-magnetic antennas of the RASS.

Similar areas with very low optical backscatter intensities have been found in other nights with low-level jets as well. 

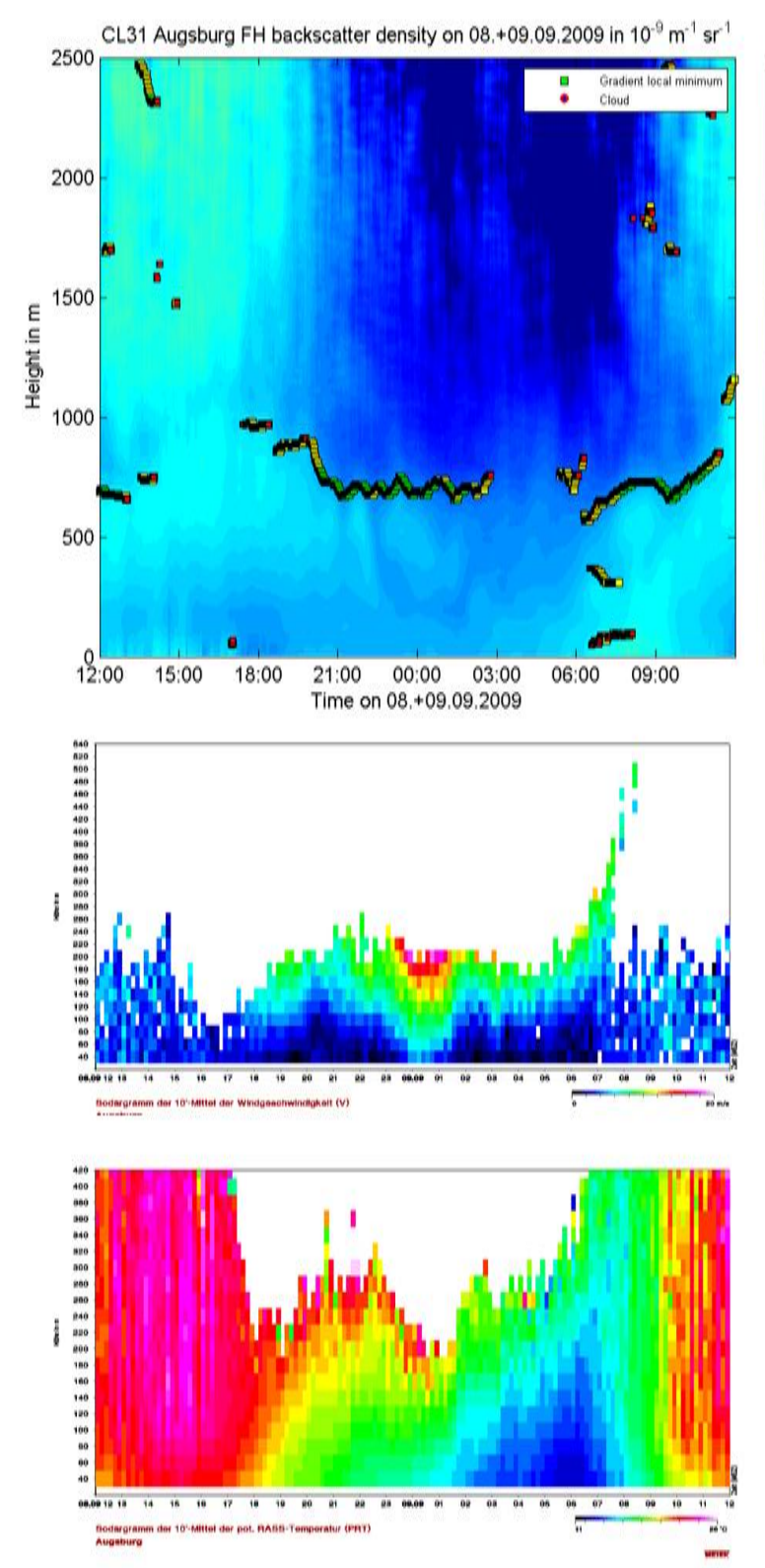

Figure 2. Time-height sections (24 hours from noon to noon, 40 to $3000 \mathrm{~m}$ above ground) of optical backscatter intensity (top), horizontal wind speed (40 to $540 \mathrm{~m}$ above ground, middle) and potential temperature (40 to $540 \mathrm{~m}$ above ground, below) over Augsburg, Germany on September 8/9, 2009. Red colours: high values, blue colours: low values. Time is GMT plus 1 which is close to local time. (See text for further details)

\subsection{Comparison to moisture information}

Atmospheric humidity has a modifying influence on the optical backscatter intensity recorded with a ceilometer. This influence is probably due to the uptake of moisture by aerosol particles which makes these particles grow.

The upper frame of Figure 3 shows an example from a ceilometer measurement from February 17, 2010, in which such an influence of atmospheric humidity is quite likely to be seen. From midnight until about 10 a.m. we observe a nocturnal stable boundary layer with high relatively high optical backscatter intensities.
This layer is filled with air having a potential temperature below $0^{\circ} \mathrm{C}$ (black to blue colours in the lower frame of Fig. 3). Green colours indicate potential temperatures between $0^{\circ} \mathrm{C}$ and $5^{\circ} \mathrm{C}$, red and purple colours temperatures between $6^{\circ} \mathrm{C}$ and $14^{\circ} \mathrm{C}$.

The optical backscatter intensity shows considerable changes especially in the upper half of the NBL just below the indicated top of the NBL at about $250 \mathrm{~m}$ above ground. The radiosonde ascent at Oberschleißheim shortly after midnight (1 a.m. local time, $00 \mathrm{GMT}$, plotted as thin, nearly vertical full and dashed lines in the upper frame of Fig. 3) shows relative humidities of more than $90 \%$. At noon relative humidities are still around $87 \%$ in the larger part of the boundary layer. A few purple dots in the upper frame at about $250 \mathrm{~m}$ height at $9 \mathrm{a} . \mathrm{m}$. and shortly before $12 \mathrm{a} . \mathrm{m}$. indicate the presence of small clouds. The small clouds at 9 a.m. are surrounded by an area of increased optical backscatter intensity. The proximity to cloud formation supports the explanation that the changes of the optical backscatter intensity are due to changes in relative humidity and not due to an increased number of aerosol particles.
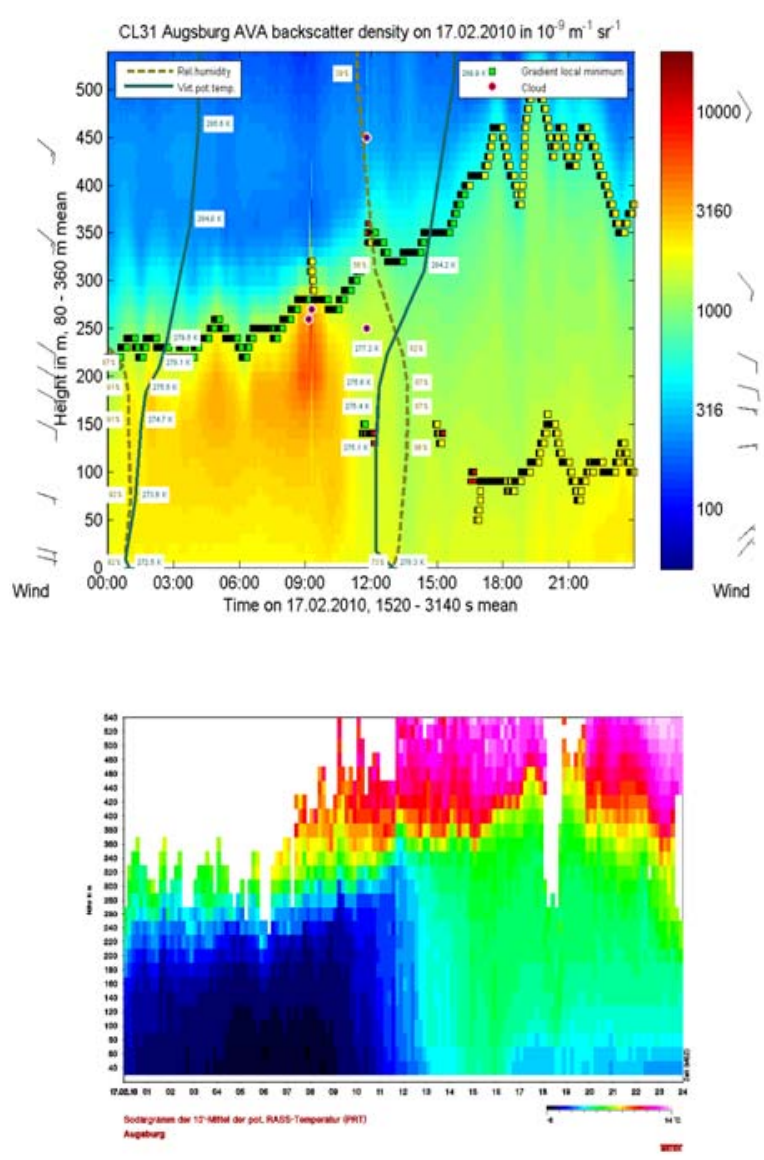

Figure 3. Time-height section (one day from midnight to midnight, 30 to $550 \mathrm{~m}$ above ground) of optical backscatter intensity (top) and potential temperature (below) at Augsburg, Germany, on February 17, 2010. Additionally, in the upper frame are plotted vertical profiles of potential temperature and relative humidity from the radiosonde of the German Weather Service at Oberschleißheim. Time is GMT plus 1 which is close to local time. (See text for further details) 


\section{DETECTION OF VOLCANIC ASH CLOUDS}

In clear sky conditions ceilometers are suited to detect volcanic ash clouds which might be a hazard for air traffic. Fig. 4 shows an example from spring 2010 (April 17) when the ash cloud from the Islandic volcano Eyjafjallajökull grounded the complete air traffic in Northern and Central Europe for several days. The time-height cross-section of optical backscatter intensity has been recorded over Augsburg in Southern Germany where the ash cloud had arrived on the evening of April 16, 2010.

The Figure shows a few clouds between midnight and 7 a.m. (brown) and a stable nocturnal boundary layer with a height of about $300 \mathrm{~m}$ until the early morning (lighter blue). Then the diurnal evolution of a convective boundary layer took place due to nearly undisturbed sunshine with a maximum height of about 1300 to $1400 \mathrm{~m}$ above ground at 4 p.m.

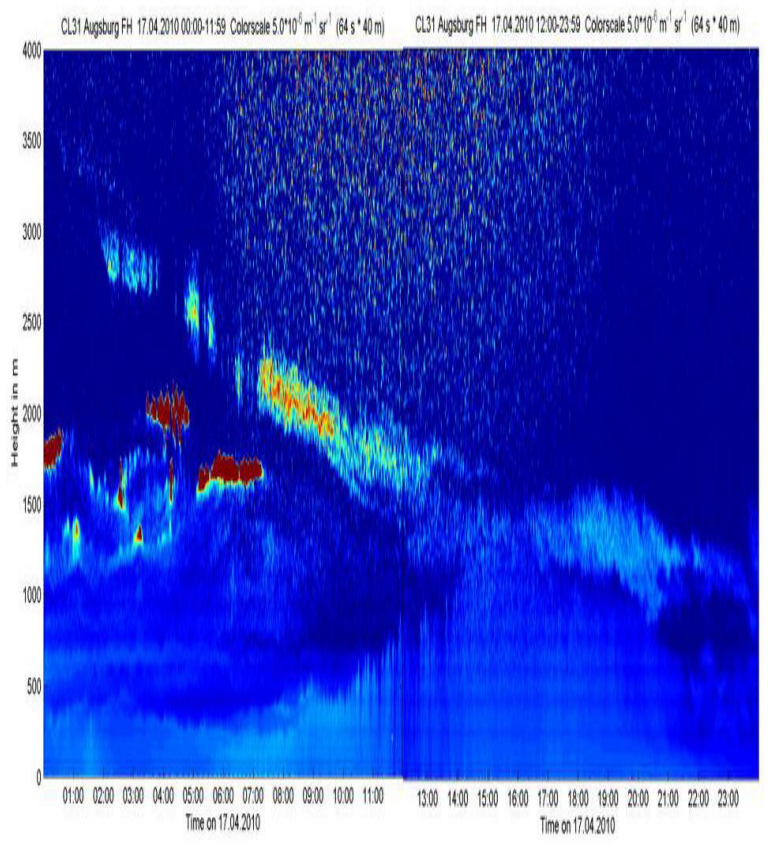

Figure 4. Time-height section (one day from midnight to midnight, 40 to $4000 \mathrm{~m}$ above ground) of optical backscatter intensity over Augsburg, Germany on April 17, 2010. Brown colours: normal water clouds, red - yellow: high backscatter values, blue colours: low values. Time is GMT plus 1 which is close to local time. Please note, the glitter around noon in heights above about $2000 \mathrm{~m}$ is due to direct sunshine on the glass window of the instrument and does not indicate any aerosol backscatter. (See text for further details)

The volcanic ash is visible from about 2 a.m. onwards as a shallow layer of a few hundred meters depth sinking from around $3000 \mathrm{~m}$ above ground in the very early morning to the top of the convective boundary layer between 3 p.m. and 4 p.m. As the synoptic data for this day do not show significant vertical velocities in the lower troposphere, the virtual sinking of the ash cloud in Figure 2 must be due to the advection of a slanted cloud with continuously lower elevations during the day. Obviously, some additional volcanic material is advected at about $1500 \mathrm{~m}$ height between 6 p.m. and 9 p.m. after the CBL had disappeared and boundary layer heights were lower than $1000 \mathrm{~m}$ again.
It remains unclear from this Figure whether material from the volcanic cloud has been mixed into the boundary layer in the afternoon. During the following days no more distinct ash clouds were observable with this ceilometer.

This Figure shows that ceilometers in principle are able to detect volcanic ash clouds. However, the volcanic nature of the cloud must be affirmed from additional information. A ceilometer itself cannot give any clues to distinguish between ash and water clouds. Such additional information could be, e.g., the depolarization ratio (see e.g. http://www.meteo.physik.unimuenchen.de/ stlidar/quicklooks/mim quicklooks.html where polarization information from a special LIDAR operated by the Meteorological Institute of the University of Munich at Maisach (about $30 \mathrm{~km}$ southeast of the Augsburg ceilometer) is available).

\section{DISCUSSION, CONCLUSIONS, OUTLOOK}

Ceilometers have become a frequently used tool to monitor cloud heights, the vertical structure of the atmospheric boundary layer and mixing-layer height without the attendance by an observer. They are operated by weather services as well as by scientific research institutions. As ceilometers are quite simple and return only one variable, the optical backscatter intensity, their output needs careful analysis.

The examples compiled here shell help with this analysis. We have noted the following important aspects:

- thermal stratification: if the distribution of the aerosol particles adapts rapidly to the thermal stratification, aerosol is a good tracer for the vertical structure of the atmospheric boundary layer;

- advection: ceilometer data must not be interpreted in a framework of local processes alone. Advection of clean air (e.g., by nocturnal low-level jets) or polluted air (e.g., desert dust or volcanic ash) can severely influence the results;

- humidity: atmospheric humidity influences the size of many aerosol particles and changes their backscatter cross-section in a non-quantifiable way.

Therefore, automated evaluation algorithms for ceilometer data have to be designed with great care. The comparison between ceilometer and RASS data will be continued.

\section{REFERENCES}

[1] Emeis, S., K. Schäfer, C. Münkel, 2008: Surfacebased remote sensing of the mixing-layer height - a review. Meteorol. Z., 17, 621-630.

[2] Emeis, S., K. Schäfer, C. Münkel, 2009: Observation of the structure of the urban boundary layer with different ceilometers and validation by RASS data. Meteorol. Z., 18, 149-154.

[3] Emeis, S., 2010: Measurement methods in Atmospheric Sciences - In situ and remote. Borntraeger, Stuttgart. $280 \mathrm{pp}$. 